\title{
Use of Serious Games to Teach Engineering Design Fundamentals
}

\author{
P. K. Raju ${ }^{1}$ Pramod Rajan ${ }^{2}$ \\ ${ }^{1,2}$ Department of Mechanical Engineering \\ 1,2 1418 WigginsHall,AuburnUniversity, Auburn,Alabama \\ rajupol@auburn.edu, rajanpr@auburn.edu
}

In this paper, we talk about the design, development and implementation of an engineering design serious game developed by Toolwire, a company with expertise in educational technologies in partnership with the Laboratory for Innovative Technology and Engineering Education (LITEE), a university center with extensive expertise in educational pedagogy and theories. The objective was to provide an active learning experience linking the engineering design process to a real-world simulation.A mixed methods approach (Creswell, 2013) was used to evaluate the effectiveness of the serious game. Analysis of the results showed that the students enjoyed working with the serious game and this experience helped them in understanding the design process in a more effective manner.

Keywords: serious games, engineering design, realworld, active learning experience

\section{Introduction}

There is a call to significantly enhance the learning and teaching of science, technology, engineering and mathematics (STEM) by K-12 students and teachers, through research and development of innovative resources, models and tools (National Science Foundation, 2013). Engineering concepts in K - 12 educational settings have the potential to address two limitations often inherent in schools. First, many students in the schools do not have engineers and scientists as role models. This limits interest in engineering and science disciplines among these students and reduces their likelihood to enter the
P. K. Raju

Department of Mechanical Engineering

418 WigginsHall,AuburnUniversity,

Auburn,Alabama,

rajupol@auburn.edu 
STEM pipeline. Second, students in these schools often feel that the material they are learning is divorced from context. This reduces their interest in the material and leads to a reduction in mastery. Smith and Weiss's (2010) findings show that curriculum materials play an important role in improving student achievement. The commercial gaming industry is moving towards providing more education-related games that can potentially benefit higher education. At the same time, education is moving towards gaming, trying to identify the areas that can help improve student engagement, cognitive skills and retention and also improve the delivery of instructional material (Kearney and Pivec, 2007; Garris et al., 2002; Kearney, 2005 and Klingberg et al., 2002).Many studies have demonstrated the use of simulations to improve student learning outcomes (Canon-Bowers, 2006; Connolly et al., 2012; Vogel et al., 2006). Educational games allow a deeper understanding of both content and concepts (Prensky, 2005).

\section{Serious Game}

A serious game can be defined as a world where the students play simulated events using characters that interact with them, and, in turn, helps them learn a concept much more thoroughly than what is possible in a classroom or in a lab session.As Prensky (2001) pointed out, games are good for two things. First, there are particular techniques or attributes of games that can help students learn complex material faster, and understand that material better. Second, games can increase the level of engagement of the trainees so that they want to play the game and they want to learn how to successfully complete the game.

\subsection{Need for Serious Games}

Educational games address the Accreditation Board for Engineering and Technology (ABET) criteria by engaging students in the learning process while meeting the following learning objectives

( Recognition of the need for lifelong learning (3i)

口 Ability to solve and define problems (3e)

口 Understand impact of engineering solutions in global and societal context (3h)

John Gill, physics teacher at Lee Scott Academy School, was planning to implement a trebuchet project with his students in a physics class. He wanted to introduce the design process in the class before starting to design the trebuchet. The engineering design serious game was chosen to introduce the design process to the students.In the following sections, the engineering design serious game will be briefly explained. The later sections will cover the implementation, evaluation, findings and limitations of this study.

\subsection{Engineering Design Game}

The game was designed to teach the engineering design process to the students. The engineering design process is inspired from the Pahl and Beitz (2007) model of the design process. The game is titled 'Engineering Heights: The Design Process in Action'. Some screen shots of the game are shown in Figure 1.

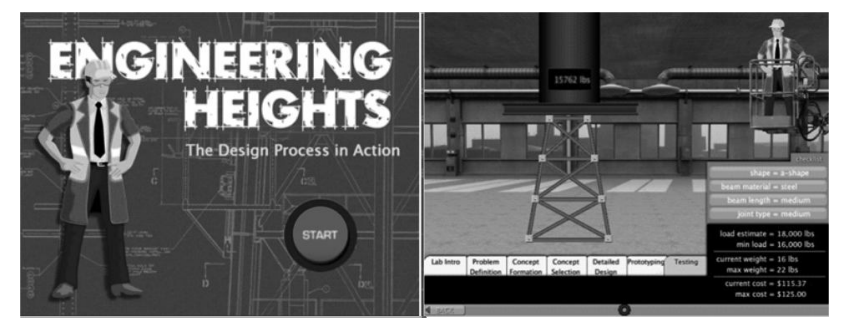

Figure 1. Screen shots from the design game

\subsubsection{Description of the Game}

The main goal of the game was to provide students with an opportunity to learn about the engineering design process in an interesting and engaging gaming environment. It also helps them understand the details involved in designing structures capable of withstanding specified loads while still remaining within cost and height constraints in an interactive manner. The design and development process of the game went through multiple iterations and stages of testing with students before it was implemented in a course. Feedback was obtained after each testing stage to ensure the learning objectives and goals of the game were achieved. Goal clarity, different levels, challenges and varied concentration levels were some of the key factors incorporated in the game based on the feedback. Figure 2 shows a basic block diagram of the game user flow experience. Each of these blocks is described in more detail below.

\section{Overview}

In this section of the game, the overall goal was defined, which was to teach students about the engineering design process. It also highlighted the need for a formal design process by presenting videos of failed bridges. The overview introduced students to basic construction materials such as the beams and joints required to build a structure. 


\section{Lab Introduction}

In this section the game detailed each of the core engineering design process steps. It then gave students an opportunity to design a structure and make decisions that affected the weight, cost and load capacity of their structure. This was done by selecting from a set of structures (square, narrow and Ashapes), materials (wood, concrete and steel), lengths (short, medium and long), and joint types (small, medium and heavy). The game let the students build their structure and showed the estimated load that their structure would withstand.

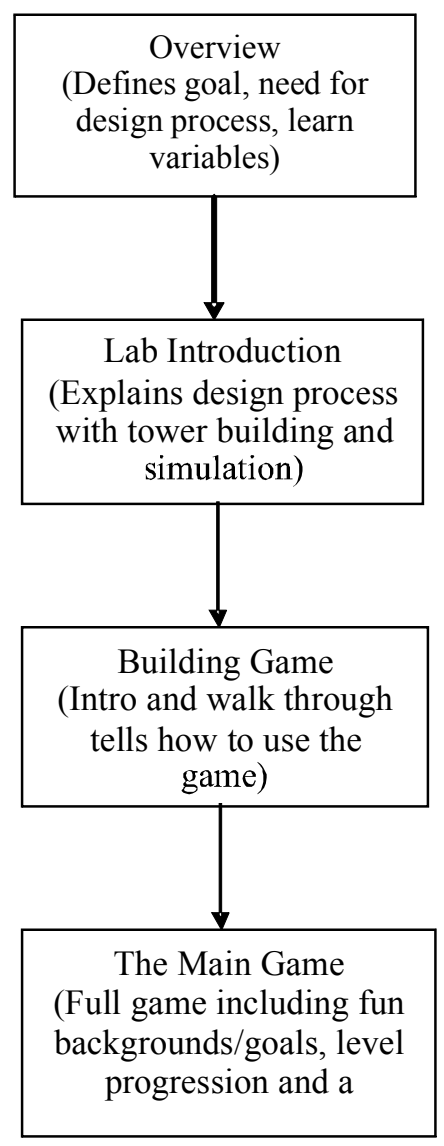

Figure 2. Game user flow experience

\section{Building Game}

In this part of the game the students were guided to use different combinations of shapes, materials and joints to design, build and test a structure from scratch. This was a tutorial in that the students had to join the dots and learn how to build their structure and then test it. There were a number of different goals (for example, achieve a minimum height, do not exceed a maximum cost, and bear a minimum load) for the students within this building game level.

\section{Main Game}

The main game consisted of three levels. The first level was a simple test tower where the students were given some constraints on weight, cost, and load before building their tower. The second level was to build a structure to hold a water tower. The third level was to build a bridge to support a train moving across it. The difficulty increased as the students progressed through the different levels. The game also computed a score for each finished level as a measure of the students' effectiveness.

\subsection{Game Dynamics and Mechanics}

The game was designed to incorporate different game dynamics and mechanics and some of them have been listed andbriefly described in Table 1.

Table 1. Summary of some of the game dynamics and mechanics

\begin{tabular}{|c|c|}
\hline Features of the game & \\
\hline $\begin{array}{l}\text { Clearly defined } \\
\text { goals in each level }\end{array}$ & $\begin{array}{l}\text { At the beginning of each level, a game character } \\
\text { narrates the goals to be achieved and the specific } \\
\text { goals, which are highlighted at the bottom of the } \\
\text { screen while the student plays the game. }\end{array}$ \\
\hline Virtual roles & $\begin{array}{l}\text { The students play the role of the project engineer } \\
\text { incharge of building the bridge using the } \\
\text { engineering design process. }\end{array}$ \\
\hline $\begin{array}{l}\text { Low, medium and } \\
\text { high concentration } \\
\text { levels }\end{array}$ & $\begin{array}{l}\text { The game offers different levels (described in the } \\
\text { game user flow experience) which require } \\
\text { different amounts of concentration (low, medium } \\
\text { and high). } \\
\text { low The Overview and Lab introduction require } \\
\text { low concentration. } \\
\text { The Building intro and Test tower level } \\
\text { require medium concentration. } \\
\text { The Water tower and train bridge level } \\
\text { require high concentration. }\end{array}$ \\
\hline Absorption & $\begin{array}{l}\text { The students become immersed in the game as } \\
\text { they progress into the water tower and train } \\
\text { bridge levels, which require higher concentration } \\
\text { levels. }\end{array}$ \\
\hline Scores & $\begin{array}{l}\text { The game provides a score at the end of each } \\
\text { stage showing the student's progression and } \\
\text { effectiveness. }\end{array}$ \\
\hline $\begin{array}{l}\text { Progress towards } \\
\text { goals }\end{array}$ & $\begin{array}{l}\text { At the end of each sequence, there is voice-over } \\
\text { which informs the player about the completion of } \\
\text { the goal. Students are continuously informed } \\
\text { about their progress after each level. }\end{array}$ \\
\hline Safely take risks & $\begin{array}{l}\text { In the overview, introduction and building game } \\
\text { stages, the students build test structures and are } \\
\text { allowed to take risks and learn from their } \\
\text { mistakes. During the main game (train bridge and } \\
\text { water tower level), the students realize that the } \\
\text { risk of failing is rising as the structures become } \\
\text { increasingly complicated to build. }\end{array}$ \\
\hline Challenges & $\begin{array}{l}\text { The game provides different challenges in all the } \\
\text { levels of the game. The challenges get harder as } \\
\text { the students' progress to higher levels, with the } \\
\text { water tower and train bridge levels being the most } \\
\text { difficult. }\end{array}$ \\
\hline Dilemma & $\begin{array}{l}\text { The game builds in a dilemma since students } \\
\text { have to choose among different materials, } \\
\text { structures and joints and learn through } \\
\text { experimentation. }\end{array}$ \\
\hline Virtual roles & $\begin{array}{l}\text { The students play the role of the project engineer } \\
\text { in- charge of building the bridge using the } \\
\text { engineering design process. }\end{array}$ \\
\hline
\end{tabular}


Screens were built according to the features discussed in Table 1. Figure 3 shows a screenshot of the game to illustrate the first row in the Table 1. The game provides clear goals in the lab introduction level, which explains the engineering design process through a tower building simulation. The engineering design process utilized here is based on Pahl's and Beitz's model of the design process and consists of six steps (Pahl and Beitz,2007): problem definition, concept formation, concept selection, detailed design, prototyping and testing. These are highlighted in the screen and repeated for emphasis. The students can go back and forth in the engineering design process by clicking on the tabs at the bottom of the screen. The tower building parameters are to the right of the screen and the students can see the parameters change in realtime based on their choices.

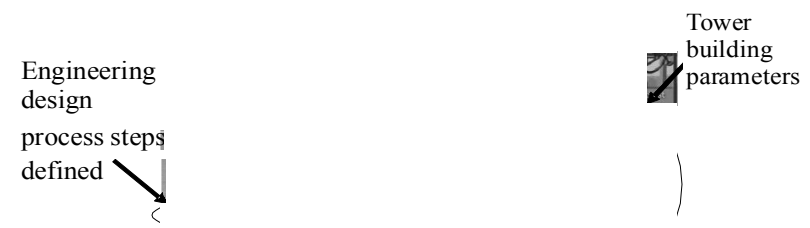

Figure 3. Screenshot of lab introduction level with engineering design process and tower building parameters as the clear goal

Figure 3 is part of a tutorial that defines each of the elements of the structure and helps the students learn how to build a structure. When the students choose an option, the system builds the structure, and teaches them about working within the load, cost, and height constraints. This tutorial requires low concentration.

Figure 4: Screenshot showing the development of a simple structure in the building intro/test tower level
Figures 4, 5, and 6 illustrate the first row of Table 2 in the form of three screenshots from the game.Figure 4 shows a screenshot of the building game level where students have to create a structure by finding an anchor point and building a simple structure within the given constrains. This level requires the students to join the dots to build the structure and allows them to test the structure repeatedly. The students must pay attention to the details and concentrate significantly before they can pass this level. The square-shaped tower structure shown in the figure required 10 long steel beams, 12 medium beams, 2 anchor joints and 9 heavy joints to build. Figure 5 shows a screenshot of the water tower level, which requires a higher level of concentration because the construction of the tower involves more beams and joints than the earlier levels. The water tower in the figure needed 19 short length wood beams, 98 medium length beams ( 24 steel and 74 wood), 42 long length beams (19 steel and 23 wood), 4 anchor joints and 70 medium weight joints to build. The game again provides feedback on failed beams and joints if the tower fails to hold the required load.Figure 6 shows a bridge that was not able to hold the train passing overit. The screen shows the complexity of the tower and required a higher amount of concentration compared to the previous levels.

Figure 5. Screenshot showing example of building a water tower

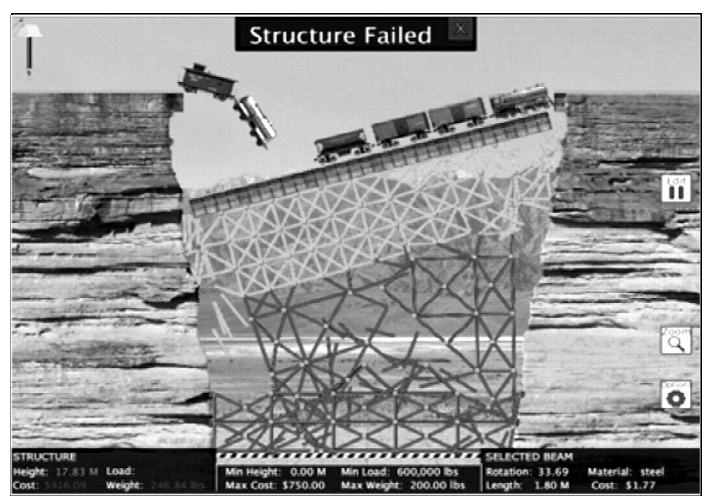

Figure 6 . Screenshot showing the failure of a train bridge under load 


\section{Implementation and Evaluation}

The game was implemented at Lee Scott Academy, a private school in Auburn, Alabama, at the senior level. The research study took place duringthe fall of 2013. The students had to go through an engineering design learning modulewhich included a lecture on the engineering design process, and a design simulation game titled "Engineering Heights: The Design Process in Action." The responses were collected from 21 students in a physics class. The demographics of the data resulted in 12 males and 9 females. All the students were Caucasians and were 17-18 years of age. In order to know whether the game is effective, it should be evaluated in the right manner. A common criticism of using new methodologies for teaching is that their effectiveness is never measured (Leidner and Jarvenpaa, 1993; Duning et al., 1993). The effectiveness of the game was evaluated using a Presage-Pedagogy-Process-Product (4P) model. It proposes that the presage conditions, along with serious games (pedagogy factor), combine to create the approach a student takes in their learning (process factors), which in turn influences the improvement in achieving outcomes (product factors). Figure 7 shows the $4 \mathrm{P}$ model with serious games being the moderating variable.Since this is an experimental study, we used the process and the product variables from the $4 \mathrm{P}$ model to test the effectiveness of the game among the students(Rajan and Raju et al., 2014).

Presage:Presage factors are factors that exist prior to the engagement and that affect the learning process. The presage factors considered in this model are gender, race and learning style. These factors interact with the serious game to affect the process and the learning outcomes. The presage factors usually constitute the independent variables in the 4P model.

Pedagogy: Different serious games can be used for both control and experimental sections. We have only one experimental section for this research study.

Process: The heart of the teaching/learning system is at the process level, where the learning-related activity produces or does not produce the desired outcomes. Process incorporates the students' learning experience. The four process variables used in this model are higher order cognitive skills, concentration, goal clarity and student enjoyment.

Product:Product is the outcome of learning. Product factors are indicators of knowledge, skills and behaviors students gained by participating in the learning process. We have identified four product factors in the research model (Rajan, 2013).
Presage Pedagogy Process Product

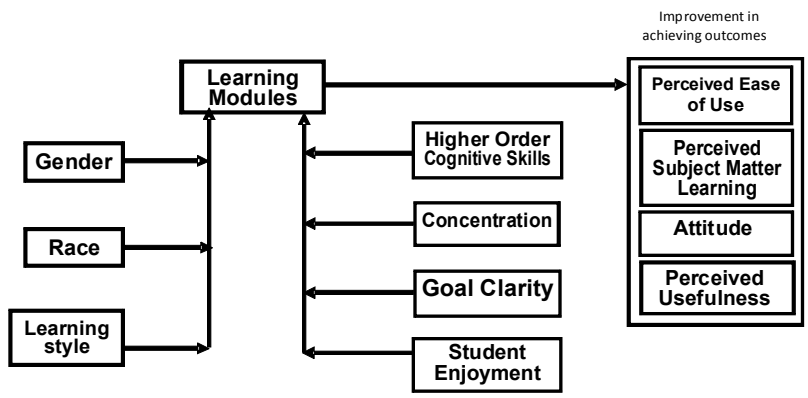

Figure 7. 4P model with serious games as the moderating variable(Rajan, 2013)

\section{Data Analysis \& Results}

Data was collected using multiple sources. An evaluation questionnaire was used to collect responses from the students. The questions used to measure the constructs in the model are shown in Table 2 with their Cronbach alpha values, which show a satisfactory degree of internal consistency reliability of the measures.

Table 2. Proposed measures and their Cronbach alphas (Rajan, 2013)

\begin{tabular}{|c|c|}
\hline $\begin{array}{l}\text { Constructs/ } \\
\text { Items }\end{array}$ & Measures \\
\hline $\begin{array}{l}\text { 1. Higher order } \\
\text { cognitive skills } \\
(\alpha=0.885)\end{array}$ & $\begin{array}{l}\text { The instructional materials in the engineering } \\
\text { design serious game helped me identify } \\
\text { engineering tools that will assist me in } \\
\text { decision-making. } \\
\text { In this engineering design serious game I } \\
\text { learned how to inter-relate important topics } \\
\text { and ideas using the instructional materials. } \\
\text { In this engineering design serious game I } \\
\text { learned how to identify various } \\
\text { alternatives/solutions to a problem using the } \\
\text { instructional materials } \\
\text { The instructional materials in this engineering } \\
\text { design serious game improved my problem } \\
\text { solving skills } \\
\text { I learned how to sort relevant from irrelevant } \\
\text { facts using the instructional materials in this } \\
\text { engineering design serious game. }\end{array}$ \\
\hline $\begin{array}{l}\text { 2. Concentration } \\
(\alpha=0.863)\end{array}$ & $\begin{array}{l}\text { I was absorbed intensely in the engineering } \\
\text { design serious game. } \\
\text { My attention was focused on the engineering } \\
\text { design serious game. } \\
\text { I concentrated fully on the engineering design } \\
\text { serious game } \\
\text { I was deeply engrossed in the engineering } \\
\text { design serious game }\end{array}$ \\
\hline $\begin{array}{l}\text { 3. Goal Clarity } \\
(\alpha=0.858)\end{array}$ & $\begin{array}{l}\text { I knew clearly what I wanted to do in the } \\
\text { engineering design serious game. } \\
\text { I had a strong sense of what I wanted to do in } \\
\text { the engineering design serious game. } \\
\text { I know what I wanted to achieve in the } \\
\text { engineering design serious game. } \\
\text { My goals were clearly defined in the } \\
\text { engineering design serious game. }\end{array}$ \\
\hline $\begin{array}{l}\text { 4. Student } \\
\text { Enjoyment } \\
(\alpha=0.899)\end{array}$ & $\begin{array}{l}\text { The serious game has been enjoyable } \\
\text { This was one of my favorite serious games } \\
\text { I had fun working on this serious game } \\
\text { I enjoyed many aspects of this serious game }\end{array}$ \\
\hline
\end{tabular}




\begin{tabular}{|c|c|}
\hline $\begin{array}{l}\text { Constructs/ } \\
\text { Items }\end{array}$ & Measures \\
\hline $\begin{array}{l}\text { 5. Perceived } \\
\text { Subject } \\
\text { Matter } \\
\text { Learning } \\
(\alpha=0.894)\end{array}$ & $\begin{array}{l}\text { I became more interested in the concept of } \\
\text { engineering design process } \\
\text { I gained a good understanding of the concept } \\
\text { of engineering design process } \\
\text { I learned to identify central ideas in the area of } \\
\text { engineering design process } \\
\text { I developed the ability to communicate clearly } \\
\text { about the concept of engineering design } \\
\text { process }\end{array}$ \\
\hline $\begin{array}{l}\text { 6. Attitude } \\
(\alpha=0.851)\end{array}$ & $\begin{array}{l}\text { From my experience in this engineering design } \\
\text { serious game I believe engineering is } \\
\text { irrelevant to my life } \\
\text { This engineering design serious game has } \\
\text { increased my appreciation for engineering. } \\
\text { From the engineering design serious game } \\
\text { experience I think engineering is highly } \\
\text { technical. }\end{array}$ \\
\hline $\begin{array}{l}\text { 7. Perceived } \\
\text { Usefulness } \\
(\alpha=0.917)\end{array}$ & $\begin{array}{l}\text { Using the engineering design serious game } \\
\text { improved my performance } \\
\text { Using the engineering design serious } \\
\text { gameenabled me to accomplish my tasks more } \\
\text { quickly } \\
\text { I found the engineering design serious game } \\
\text { useful } \\
\text { Using the engineering design serious game } \\
\text { increased my productivity } \\
\text { Using the engineering design serious game } \\
\text { enhanced my effectiveness } \\
\text { Using the engineering design module made it } \\
\text { easier to do my work }\end{array}$ \\
\hline $\begin{array}{l}\text { 8. Perceived } \\
\text { Ease of Use } \\
(\alpha=0.90)\end{array}$ & 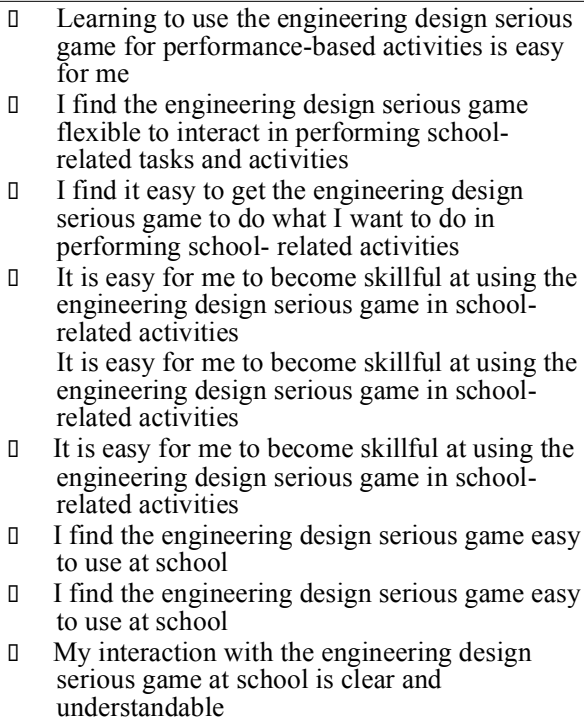 \\
\hline
\end{tabular}

The questions asked students to rate the extent of their agreement on the constructs on a 5-point Likert scale mentioned above in the 4P model.Both qualitative and quantitative analyses were conducted to find out the effectiveness of the serious game. One sample t-test was conducted on the data. Table 3 shows the results of one sample test of the process and the product variables. The findings indicate that the means of all the product and process variables are significantly higher than the neutral rating of 3.0. This might suggest that the game provided good concentration and goal clarity. The results also suggest that the students perceived the game to be useful and easy to use. The results in the table also suggest that the students enjoyed the game and they perceive the game to be helpful in learning and improving higher order cognitive skills.

Table 3. Results of one sample t-test with a test value of 3.0(Rajan and Raju et al., 2014)

\begin{tabular}{|l|c|c|c|c|c|}
\hline Variables & Mean & $\begin{array}{c}\text { Std. } \\
\text { Deviation }\end{array}$ & $\mathrm{t}$ & $\mathrm{df}$ & $\mathrm{p}$-value \\
\hline Concentration & 3.99 & .72 & 6.27 & 20 & .000 \\
\hline Perceived Usefulness & 3.31 & .63 & 2.27 & 20 & .034 \\
\hline Goal Clarity & 3.99 & .76 & 5.99 & 20 & .000 \\
\hline Perceived Subject Matter Learning & 3.75 & .59 & 5.81 & 20 & .000 \\
\hline Higher Order Cognitive Skills & 3.65 & .65 & 4.58 & 20 & .000 \\
\hline Perceived Ease of Use & 3.65 & .81 & 3.69 & 20 & .001 \\
\hline Student Enjoyment & 3.60 & .83 & 3.28 & 20 & .004 \\
\hline Attitude Towards Subject Matter & 3.67 & .57 & 6.27 & 20 & .000 \\
\hline
\end{tabular}

Scale: 1 -Strongly disagree; 3 - Neither agree nor disagree; 5 - Strongly agree

A correlational analysis was performed to look at significant relationships between the product and the process variables and the results of the analysis are shown in Table 4 . The results indicated a statistically significant relationship between majority of the process and product variables (Rajan and Raju et al., 2014).

Table 4. Results of correlational analysis between product and process variables (Rajan and Raju et al., 2014)

\begin{tabular}{|c|c|c|c|c|}
\hline Product & $\begin{array}{c}\text { Perceived } \\
\text { Subject } \\
\text { Matter } \\
\text { Learning }\end{array}$ & Attitude & $\begin{array}{c}\text { Perceived } \\
\text { Ease } \\
\text { of Use }\end{array}$ & $\begin{array}{c}\text { Perceived } \\
\text { Usefulness }\end{array}$ \\
\hline $\begin{array}{c}\text { Higher Order } \\
\text { Cognitive Skills }\end{array}$ & $\begin{array}{c}\mathrm{r}=0.882 \\
\mathrm{p}=.000\end{array}$ & $\begin{array}{l}\mathrm{r}=0.849 \\
\mathrm{p}=.000\end{array}$ & $\begin{array}{l}\mathrm{r}=0.728 \\
\mathrm{p}=.000\end{array}$ & $\begin{array}{l}\mathrm{r}=0.536 \\
\mathrm{p}=.012\end{array}$ \\
\hline Student & $\mathrm{r}=0.789$ & $\mathrm{r}=0.827$ & $\mathrm{r}=0.642$ & $\mathrm{r}=0.661$ \\
Enjoyment & $\mathrm{p}=.000$ & $\mathrm{p}=.000$ & $\mathrm{p}=.002$ & $\mathrm{p}=.001$ \\
\hline Goal Clarity & $\mathrm{r}=0.658$ & $\mathrm{r}=0.471$ & $\mathrm{r}=0.518$ & $\mathrm{r}=0.279$ \\
& $\mathrm{p}=.001$ & $\mathrm{p}=.031$ & $\mathrm{p}=.016$ & $\mathrm{p}=.220$ \\
\hline Concentration & $\mathrm{r}=0.453$ & $\mathrm{r}=0.579$ & $\mathrm{r}=0.346$ & $\mathrm{r}=0.412$ \\
$\mathrm{p}=.039$ & $\mathrm{p}=.006$ & $\mathrm{p}=.131$ & $\mathrm{p}=.063$ \\
\hline
\end{tabular}

r- Pearson correlation coefficient.

*High values of $\mathrm{r}(>0.50)$ indicate strong relationship between two variables (Cohen, 1998) 
Students learned about the engineering design process from the serious game.Comments from students collected at a focus group session indicated that the serious game helped in understanding the engineering design process through a real-world tower building example. The student group that is involved in the robotics team at the school said, "We did not have a design process in building our robot and we get a score when we report our process through our Project Engineering Notebook. The game really helped in improving our knowledge about the design process and in getting a higher score on the Project Engineering Notebook." Another student said "I like the game because you get to try different shapes and test it. This is not possible in the real-world." The students also said that they would like to learn more concepts through a fun, engaging and gaming environment. Student comments also showed that individuals were provided a challenging, compelling learning experience through playing the serious game. Students also indicated that the game was fun, enjoyable and, for many, preferable to learning compared to other methods(Rajan and Raju et al., 2014).

\section{Conclusions and Limitations}

Both the qualitative and the quantitative analysesrevealed greater gains in perceptions of students who participated in the research study, which shows that a serious game is a good instructional tool to teach engineering concepts to K-12 students. The qualitative analysis revealed the following:

1. The students liked the learning experience from playing the serious game.

2. Goal clarity, concentration and student enjoyment are some of the key elements to achieve better learning effectiveness in a serious game learning environment.

The quantitative analysis showed thatall the mean ratings for the constructs were favorable (above the neutral rating 3.0) to the gaming environment. The use of serious games in a classroom is one way to engage and motivate students.

Some limitations of this study are: 1) The study needs to be conducted in a control/experimental environment to see the differences between the traditional learning environment and a serious game learning environment. 2)All the measures of learning outcomes in this study are all based on students' perception. Any objective measures of performance that tests the students understanding of the design process would be a good addition to the study.

\section{Implications for Practice}

This study suggests three implications to serious game developers, game researchers and industry practitioners. First there is much less research that establishes links between game features and learning outcomes at K-12 education level and this study shows that students like to learn engineering content through serious games and perceive them to be fun and engaging. Second, the development and testing of the game requires a substantial amount of time. The game was tested with the students during the design and development stage and continuous improvements were made to achieve best game dynamics and mechanics. So it is very important for game developers and researchers to understand that rigorous testing is necessary at different stages of development of a serious game. Third, we observed that there is a certain amount of frustration in the serious game learning environment. So the teachers and trainers must be well prepared to answer questions and reassure students who become frustrated with technical and game difficulties.

\section{Acknowledgments}

We thank our industrial partners, Toolwire Inc. for working with us in providing the necessary technical help in developing this serious game. We particularly thank Dayvid Jones and Michael Watkins and their team in helping us in the design and development of this serious game. We also thank Dr. John M. Winters and John Gill for their support in implementing the game at Lee Scott Academy School. This project was funded by the National Science Foundation, IIP \#1110223. The PI of the project was Steve Lynch from Toolwire Inc. and Co-PI Dr. P. K .Raju from Auburn University. Any opinions, findings, and conclusions or recommendations expressed in this paper are those of the authors and do not necessarily reflect the views of the National Science Foundation.

\section{References}

AdamNordin(2013),http://www.milkeninstitute.org/ events/gcprogram.taf?function $=$ detail\&eventid $=\mathrm{gc} 1$ $3 \& \mathrm{EvID}=4114$, Accessed on July 1, 2015

Albers, A., Sauter, C., Maier, T., Geier, M., \& Ottnad, 
J. (2009, January). Academic Engineering Design Education in a Realistic Environment. ASME 2009 International Design Engineering Technical Conferences and Computers and Information in Engineering Conference (pp. 565-573).

Cannon-Bowers, J. (2006). The state of gaming and simulation. In training 2006 conference and expo, Orlando, FL.

Cohen, J. (1988). Statistical power analysis for the behavioral sciences (2nd edition). Hillsdale, NJ: Lawrence Erlbaum Associates

Connolly, T. M., Boyle, E. A., MacArthur, E., Hainey, T., \& Boyle, J. M. (2012). A systematic literature review of empirical evidence on computer games and serious games. Computers \& Education, 59(2), 661686.

Creswell, J. W. (2013). Research design: Qualitative, quantitative, and mixed methods approaches. Sage Publications, Incorporated pp 219-224.

Duning, B.S., M.J. Van Kekerix, and L.M. Zaborowski (1993), "Reaching Learners through Telecommunications," Jossey-Bass Publishers, San Francisco, CA

Garris, R., Ahlers, R., \& Driskell, J. E. (2002). Games, motivation, and learning: A research and practice model. Simulation \& gaming, 33(4), 441-467.

Gattie, D. K., \& Wicklein, R. C. (2007). Curricular value and instructional needs for infusing engineering design into K-12 technology education, Journal of Educational Technology, Vol. 19 No.1.

Hailey, C., Erekson, T., Becker, K., \& Thomas, M. (2005). National Center for Engineering and Technology Education. The Technology Teacher. 64(5) 23-26.

Kearney, P. (2005). Cognitive calisthenics: Do fps computer games enhance the player's cognitive abilities? Paper presented at the DiGRA 2005 Changing Views: Worlds in Play International Conference, Vancouver, Canada.

Kearney, P. \& Pivec, M. (2007). Recursive loops of game based learning. In Proceedings of World Conference on Educational Multimedia, Hypermedia and Telecommunications. Vancouver, 2007, pp. 2546 $-2553$
Klingberg, T., Forssberg, H., \& Westerberg, H. (2002). Increased brain activity in frontal and parietal cortex underlies the development of visuospatial working memory capacity during childhood. Journal of cognitive neuroscience, 14(1), 1-10.

Leidner, D.E., and S.L. Jarvenpaa, (1993) "The Information Age Confronts Education: Case studies on Electronic Classrooms, "Information systems Research, 4(1), p 24-54

National Science Foundation, (2013). http://www.nsf.gov/pubs/2013/nsf13601/nsf13601.h tm, Accessed July 1, 2015.

Pahl, G., Beitz, W., Schulz, H. J., \& Jarecki, U. (2007). Engineering design: a systematic approach: Springer.

Prensky, M. (2001). Digital natives, digital immigrants part 1. On the horizon, 9(5), 1-6.

Prensky, M. (2005). "Engage Me or Enrage Me": What Today's Learners Demand. Educause review, 40(5), 60.

Rajan, P.(2013). Development and Testing of Innovative Instructional Materials to Improve Student Learning in Engineering Classes - Case Studies, Smart Scenarios and Serious Games. Retrieved from Auburn Electronic Theses and Dissertation, 2013, Available from: http://hdl.handle.net/10415/3839

Rajan, P., Raju, P.K., Gill, J. T. (2014) Impact of Engineering Design Serious Game on Student Learning in a K-12 Curriculum. 121st ASEE Annual Conference \& Exposition,June 15-18, Indianapolis

Smith PS, Weiss IR. (2010). Report of the Project Activity and Findings.Assessing Teacher Learning About Science Teaching (ATLAST)(EHR-0335328). Chapel Hill, NC: Horizon Research Inc., h t $\mathrm{t} p$ : / / w w w . h o r i $\quad$ z o n research.com/atlast/uploads/Annual\%20Reports/Yr $\% 207 \% 20$ Activities\%20and\%20Findings \%20EHR0335328.pdf, Accessed July 1, 2015.

Vogel, J. J., Vogel, D. S., Cannon-Bowers, J., Bowers, C. A., Muse, K., \& Wright, M. (2006). Computer gaming and interactive simulations for learning: A meta-analysis. Journal of Educational Computing Research, 34(3), 229-243. 